\title{
Avulsion of the anterior papillary muscle of the mitral valve due to non-penetrating trauma to the chest
}

\author{
R PILLAI, S W FOUNTAIN, S A QURESHI, A MITCHELL, ALUN REES
}

From Harefield Hospital, Harefield, Middlesex

Mitral regurgitation due to avulsion of a papillary muscle is a rare complication of closed injury to the anterior chest wall. Rupture of the chordae tendinae producing mitral regurgitation is more commonly found. ${ }^{1-4}$ Avulsion of the anterior papillary muscle has been reported as a finding at necropsy, ${ }^{56}$ but to our knowledge survival after such an injury has not been reported previously. We now report such a case.

\section{Case report}

A 28-year-old man was admitted to a district general hospital with dyspnoea after trauma to the anterior chest wall caused by a flying metal bar. On examination the only external evidence of injury was a transverse superficial laceration $3 \mathrm{~cm}$ long, overlying the second intercostal space. There was a soft systolic murmur at the cardiac apex and a few bilateral basal crepitations. Twenty-four hours later there was sudden deterioration in his condition and he developed signs of pulmonary oedema. He was transferred to our unit. On admission he had a regular pulse rate of 160 beats $/ \mathrm{min}$ and a blood pressure of $100 / 80 \mathrm{~mm} \mathrm{Hg}$. There was a systolic thrill at the apex and a grade $4 / 4$ pansystolic murmur radiating to the axilla. The electrocardiogram showed sinus rhythm, Q waves in lead V3, and ST segment changes with $T$ wave inversion in leads V2-V6. The chest radiograph confirmed pulmonary oedema with no evidence of rib fracture. The M-mode echocardiogram showed excessive excursion of the anterior mitral leaflet, with a normal left ventricle and left atrium (fig 1). At cardiac catheterisation severe mitral regurgitation into a normal left atrium was seen. There was no aortic regurgitation and the coronary arteries were normal.

After these investigations the patient's condition deteriorated further and an emergency operation with cardiopulmonary bypass was performed. External and internal cardiac massage was necessary because of inadequate output, but proved ineffective owing to the severe mitral regurgitation. Through a left atriotomy the mitral leaflets appeared normal, but the anterior papillary muscle was found to be avulsed at the base (fig 2). There was contusion of the anterior surface of the left upper lobe of the lung and the left ventricular outflow tract. The mitral valve was replaced with a Carpentier-Edwards porcine xenograft. The patient is alive eight months after surgery, though he has a residual neurological deficit consisting of bilateral lateral popliteal nerve palsy.

\section{Discussion}

Cardiac lacerations may result from crush or stretch forces

Address for reprint requests: Mr R Pillai, Brompton Hospital, London SW3 6HP.

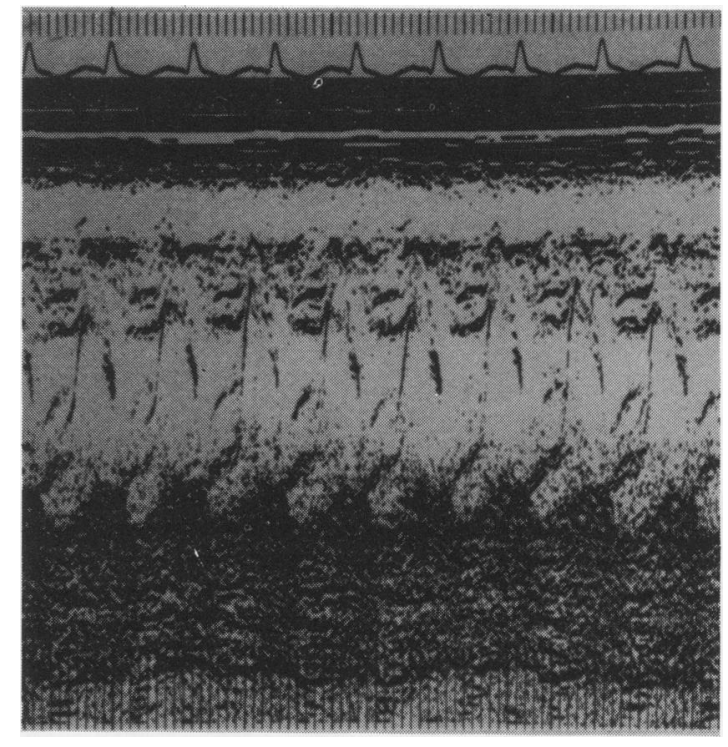

Fig $1 M$-mode echocardiogram showing excessive excursion of the anterior mitral leaflet.

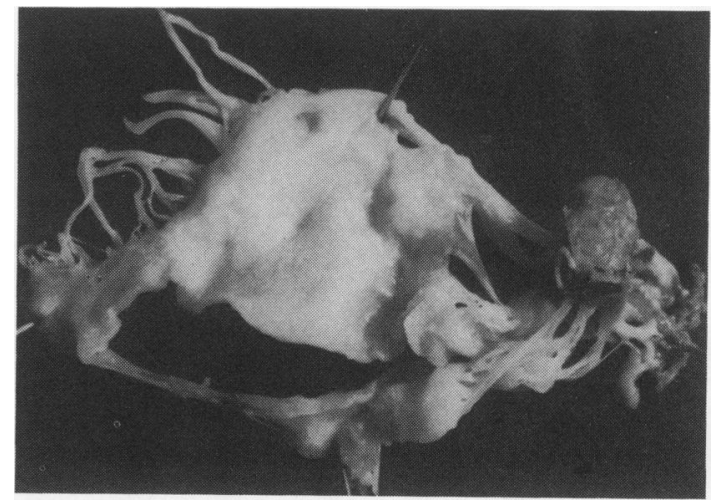

Fig 2 Papillary muscle avulsed at the base with intact chordae tendinae.

accompanying non-penetrating trauma to the chest wall. The papillary muscles, the interventricular septum, or the free ventricular wall may be ruptured.$^{1478}$ Experimental evidence indicates that intraventricular pressures of over $320 \mathrm{~mm} \mathrm{Hg}$ are required to cause any form of cardiac rupture. ${ }^{8}$ Such pressures 
have been achieved in vitro by retrograde perfusion through the aortic valve. Rupture of the mitral or tricuspid valves may occur during diastole by compression of the heart with obstruction to the outflow tract ${ }^{46}$; much higher intraventricular pressures, however, are likely to be achieved if such compression with outflow tract obstruction occurs in the isometric phase of ventricular systole. Cardiac injuries may occur more commonly in the left heart than the right owing to the higher pressure. ${ }^{14}$

Lesions affecting the papillary muscles of the mitral valve resulting from blunt trauma are rare. A review of necropsy findings in 546 patients revealed no cases of isolated mitral valve injury. ${ }^{1}$ Rupture of the chordae tendinae is more commonly reported. ${ }^{2369}$ The usual cause is an industrial or automobile accident. The initial symptoms vary. A systolic murmur is usually present, although diastolic murmurs have been reported. ${ }^{6}$ Congestive cardiac failure soon develops. Electrocardiographic changes such as Q waves, ST elevation, and T wave inversion have been reported after blunt trauma. ${ }^{16}$ These are due to myocardial contusion or necrosis ${ }^{6}$ and may be transient.

In contrast to tricuspid regurgitation resulting from blunt trauma, ${ }^{10}$ papillary muscle rupture of the mitral valve is catastrophic. ${ }^{4}$ It rapidly leads to left ventricular failure, with death in hours or days. Early recognition and operation offer the best chance of survival.

\section{References}

' Parmley LF, Manion WC, Mattingly TW. Non-penetrating traumatic injury of the heart. Circulation 1958;18:371-96
${ }^{2}$ Menges H, Ankeney JL, Hellerstein HK. Ruptured mitral chordae tendinae. Circulation 1964;30:8-13

${ }^{3}$ Bouvrain Y, Binet JP, Fortin P, et al. Four cases of rupture of the chordae tendinae of the mitral valve treated by valvuloplasty. Bull Soc Med Hosp (Paris) 1965;116:567-71.

${ }^{4}$ Liedtke AJ, DeMuth WE. Non-penetrating cardiac injuries: a collective review. Am Heart J 1973;86:687-97.

${ }^{5}$ Glendy RE, White PD. Non-penetrating wounds of the heart. Rupture of papillary muscle and contusion of heart resulting from external violence: case report. Am Heart $J$ 1936;11:366-9

${ }^{6}$ McLaughlin JS, Cowley RA, Smith G, Matherson NA. Mitral valve disease from blunt trauma. J Thorac Cardiovasc Surg 1964;48:261-71.

${ }^{7}$ Szakacs A. Traumatic rupture of papillary muscle with unrecognised cardiac tamponade. $J$ Forensic Sci 1966;2:174-6.

${ }^{8}$ Lyon RT, Levett JM, Sheridan JM, Glagov SG, Anagnostopoulos CE. Myocardial rupture. III - Chamber pressure, rate of distention and ventricular disruption in isolated hearts. Ann Thorac Surg 1979;6:554-8.

${ }^{9}$ Roberts WC, Brainwald E, Morrow AG. Acute severe mitral regurgitation secondary to ruptured chordae tendinae. Circulation 1966;33:58-62.

${ }^{10}$ Jahnke EJ, Nelson WP. Aaby GV, Fitzgibbon GB. Tricuspid insufficiency: the result of non-penetrating cardiac trauma. Arch Surg 1967;95:880-6. 